JOURNAL OF HEALTH SCIENCE AND PREVENTION

http://jurnalfpk.uinsby.ac.id/index.php/jhsp

ISSN 2549-919X (e)

\title{
Cortisol Level Related Glucose Intolerance in Adult with Obese Central
}

\section{Nurzakiah Hasan ${ }^{1 *}$, Veni Hadju², Nurhaedar Jaf ${ }^{2}{ }^{2}$, Ridwan Mochtar Thaha $^{3}$}

1) Doctoral Program, Faculty of Public Health Hasanuddin University, Makassar, Indonesia

2) Nutrition Department, Public Health Faculty, Hasanuddin University, Makassar, Indonesia

3) Health Promotion Department, Public Health Faculty, Hasanddin University, Makassar, Indonesia

nurzakiahksruh@gmail.com

DOI: http://doi.org/10.29080/jhsp.v3i3S.299

\section{Keywords}

Cortisol; Intolerance;

Glucose;

Diabetes

mellitus

\begin{abstract}
Obesity is associated with an increased risk of diseases, especially central obesity. Central obesity is a risk factor of glucose intolerance. Glucose intolerance is the beginning of diabetes mellitus. Many factors influence glucose intolerance. The aim of this study was to investigate the relationship between cortisol levels and some other factors related glucose intolerance. This study was a cross-sectional study from 12 high schools in Makassar. The analysis for this study was performed with 54 teachers. Characteristic samples, anthropometry, fasting blood glucose (FBG), cortisol were measured for all samples. Blood plasma glucose was measured from venous blood samples. Respondents were mostly female (85.2\%), married (87\%), bachelor's degree $(79,6 \%)$ and Buginesse (66.7\%). The average age of respondents was 49.37 years. The results showed a significant relationship formula: between high cortisol levels in respondents who experienced glucose intolerance $(\mathrm{p}=0.043)$. Stress variables did not show a significant relationship, but the average score was higher in those who experienced glucose intolerance than those who had normal glucose. The frequency of consumption of carbohydrates, fats, proteins, and Body mass index (BMI) did not show a significant relationship with glucose intolerance. Cortisol levels are associated with glucose intolerance in adults with central obesity.
\end{abstract}

\section{Introduction}

Obesity has become a major global health challenge problem. Not only because because of risks to health caused, but also because no country has successfully overcome it nationally[1]. Also, obesity, especially central obesity, often occurs in adults[2]. Central obesity is a risk factor for increased blood sugar levels including glucose intolerance.

Glucose intolerance which is also commonly known as prediabetes can be an early diagnosis of diabetes mellitus[3]. Furthermore, glucose intolerance is one of the parameters of metabolic syndrome[4] which is a risk factor for diabetes mellitus[5]. People with high blood glucose but not yet diagnosed with diabetes are still at risk for diabetes complications. Good management needs to be done to prevent this complication[3]. One of them is to recognize the various risk factors associated with glucose intolerance.

Glucose intolerance is related to several risk factors. A research in Pakistan shows women have a 2fold risk of experiencing glucose intolerance than men. In this study, age and hypertension are also risk factors for glucose intolerance[6]. Other risk factors were percentage body fat, BMI, higher social economy[7], and dietary pattern[8,9].

Cortisol is a hormone released during stress and associated with gluconeogenesis[10]. Increased cortisol hormone in people who have diabetes mellitus has been widely studied [11,12,] but in people who have glucose intolerance, this study is still lacking. This study aims to look at the relationship between cortisol levels and several other risk factors associated with glucose intolerance in the adult group with central obesity. 


\section{Methods}

This cross-sectional study was conducted on a group of teachers in Makassar City. This study involved 12 selected schools and was part of a cohort study, educating teachers as an effort to prevent metabolic syndrome. Schools were selected based on the highest number of teachers from the data from the provincial education office South Sulawesi in 2015. In the baseline data collection, there were 200 respondents who had taken their blood to examine the parameters of the metabolic syndrome. All teachers who were not diagnosed with diabetes mellitus, heart disease, stroke; not pregnant; and not retiring in March 2019 could become a respondent in this cohort study.

For further research, we selected 86 samples representing 12 schools randomly. The number of samples that can be analyzed for this study was 54 people ( 8 men and 44 women). We merely analyzed respondents whose having central obese and FBG $<126 \mathrm{mg} / \mathrm{dl}$. Demographic characteristics (age and sex), stress levels were measured using a questionnaire through interviews with respondents. Interview and measurement of anthropometry (weight, height, waist circumference/WC) were carried out by trained personnel taken from undergraduate nutrition students public health faculty of Hasanuddin University.

Height measurements were carried out where respondents had removed footwear and hats using microtoice; weight measurement is done where the respondent has issued all the burdensome objects from his pocket, including the shoes, the measurements are made using Camry scales; Abdominal circumference is measured using a measuring tape.

Glucose intolerance was identified using standards of medical care in diabetes by American Diabetes Association (100-125 mg/dl)3 using FBG from previous study data. Blood collection is carried out by trained staff laboratory.

Cortisol was measured using the enzyme immunoassay test method. This method has been used in the previous studies[13]. Reagents used in the Diagnostic Biochem Canada Inc brand, where cortisol uses reagents with Ref can-C-270 and examinations were carried out at the Laboratory of Hasanuddin University Hospital.

The frequency of carbohydrate consumption, protein consumption, and fat consumption was measured using a food frequency questionnaire (FFQ). The questionnaire was validated in another school, and only one food item was released because less than $10 \%$ of respondents consumed it. The interview was conducted by trained personnel taken from undergraduate nutrition students public health faculty of Hasanuddin University.

\section{Results}

Based on the characteristics of the sample, female respondents more than men respondents $(85.2 \%$ vs $14.8 \%$ ). The average age of the sample is 49.37 years. Most respondents were married, but some were divorced ( $87 \%$ vs $13 \%)$. Most respondents have a bachelor degree on education level (79.6) and come from the Buginesse (66.7\%) Table 1.

Cortisol levels in the blood showed a significant relationship with glucose intolerance, where respondents who experienced glucose intolerance had higher cortisol than those with normal glucose levels (10.4 \pm 5.9 vs $6.6 \pm 2.1 ; p$-value $=0.043)$. The average stress level score for respondents who experienced glucose intolerance was also higher than those who had normal glucose levels $(33.1 \pm 15.0$ vs $28.3 \pm 5.4)$ but it did not show a significant relationship, BMI variables, frequency of carbohydrate consumption, frequency of protein consumption, and frequency of carbohydrate consumption did not show a significant relationship with glucose levels. Table 2 .

Table 1. Characteristic of Sample

\begin{tabular}{ll}
\hline Variable & $\mathbf{n}=\mathbf{5 4}(\mathbf{0})$ \\
\hline Sex & $8(14.8)$ \\
Male & $44(85.2)$ \\
Female & $49.37 \pm 5.5$ \\
Age & \\
Marital status & $47(87)$ \\
Married & $7(13)$ \\
Divorce & \\
Education & $11(20.4)$ \\
Magister degree & \\
Ethnicity & $33(66.7)$ \\
Buginesse & $7(13.0)$ \\
Makassar & $1(1.9)$ \\
Mandar & $10(18.5)$ \\
Others &
\end{tabular}


Table 2 Relationship between glucose intolerance and risk factors

\begin{tabular}{|c|c|c|c|}
\hline & $\begin{array}{l}\text { Glucose } \\
\text { intolerance } \\
(n=13)\end{array}$ & $\begin{array}{l}\text { Normal } \\
\text { glucose }(n=41)\end{array}$ & \\
\hline Variable & Mean \pm SD & Mean \pm SD & P-value \\
\hline Cortisol & $10.4 \pm 5.9$ & $6.6 \pm 2.1$ & $0.043^{*}$ \\
\hline Stress level score & $33.1 \pm 15.9$ & $28.3 \pm 5.4$ & 0.103 \\
\hline BMI & $25.6 \pm 2.5$ & $25.8 \pm 2.2$ & 0.774 \\
\hline $\begin{array}{l}\text { Frequency of carbohydrate } \\
\text { consumption }\end{array}$ & $3.3 \pm 0.8$ & $3.5 \pm 0.9$ & 0.686 \\
\hline $\begin{array}{l}\text { Frequency of protein } \\
\text { consumption }\end{array}$ & $2.18 \pm 2.1$ & $2.8 \pm 2.9$ & 0.460 \\
\hline $\begin{array}{l}\begin{array}{l}\text { Frequency of fat } \\
\text { consumption }\end{array} \\
\end{array}$ & $0.6 \pm 0.6$ & $1.3 \pm 2.2$ & 0.119 \\
\hline
\end{tabular}

\section{Discussion}

This study shows that there is a relationship between cortisol levels in the blood and glucose intolerance. Cortisol levels increase with increasing blood glucose levels. This study is similar to previous studies which showed that there was an increase in cortisol levels in the blood in respondents who experienced glucose intolerance[14]. Cortisol is released in stressful conditions which result in decreased insulin sensitivity. As a result, the level of glucose in the blood increases. Previous research has shown that cortisol increase is one of the factors causing diabetes mellitus15. A meta-analysis by Chen et al show prevalence of depression was moderately increased in prediabetes compared normal glucose $(1.11,95 \%$ confidence interval (CI) 1.03-1.19)[16].

The Cennai Urban Rural Epidemiology study (The Cures) conducted in India show a result that depression is associated with glucose intolerance and the prevalence of depression which is higher in respondents who have diabetes mellitus[17]. The results of this study also showed the same, where the stress score in the group that experienced glucose intolerance was higher than those who had normal glucose. However, it did not show a significant relationship. Differences in stress levels in the workplace can be the cause of no association between stress scores and metabolic syndrome parameters, including glucose intolerance [18].

There is no relationship between BMI and glucose intolerance. The samples we analyzed were only those with central obesity. Whereas central obesity with BMI correlates with each other. So that the sample has an average BMI that is not much varied between groups that experience glucose intolerance with normal glucose. Glucose this can be seen in Table 2. This differs from previous studies that show more intolerance glucose in respondents who experienced central obesity[19].

In this study, we do not found a relationship between the frequency of carbohydrate, protein, and fat consumption. This result is different from another study in Canada, glucose intolerance was related to high consumption protein in Canadian Inuit Population study[20]. Our data just used FFQ from the previous study, so it cannot show the amount of energy consumed by each nutrient. It only shows the frequency of the food consumed every day.

This study has some limitations. First the cross sectional study design, which makes the inference of causality difficult. Second, we used the data of FBG only, while the determination of glucose intolerance also requires the measurement of blood sugar levels 2 hours after meals[3], This allows the bias in determining respondents who experience glucose intolerance.

\section{Conclusion and Suggestion}

In conclusions, our study shows that levels are associated with glucose intolerance in the adult with obese central. Respondents who have high glucose levels also have high cortisol levels. These associations may be modified by stress level in the workplace. This study was only conducted in the adult group with small sample size. Research needs to be done with larger sample size and a better research design, so that it can strengthen the results of this study.

We thank to Ministry of Research, Technology and Higher Education funding the study. We also to supported from Health College Baramuli and Public Health Faculty, Hasanuddin University, We thank to the headmaster, staffs, and teachers participating in this study. We would also like to thank to of the research assistants who helped with data collection. 


\section{References}

1. Ng M, Fleming T, Robinson M, et al. Global, regional, and national prevalence of overweight and obesity in children and adults during 1980-2013: a systematic analysis for the Global Burden of Disease Study 2013. The lancet. 2014;384(9945):766-781.

2. Zhao G, Ford ES, Li C, Tsai J, Dhingra S, Balluz LS. Waist circumference, abdominal obesity, and depression among overweight and obese US adults: National Health and Nutrition Examination Survey 2005-2006. BMC psychiatry. 2011;11(1):130.

3. Association AD. Standards of medical care in diabetes-2015 abridged for primary care providers. Clinical diabetes: a publication of the American Diabetes Association. 2015;33(2):97.

4. Alberti K, Eckel RH, Grundy SM, et al. Harmonizing the metabolic syndrome a joint interim statement of the international diabetes federation task force on epidemiology and prevention; national heart, lung, and blood institute; American heart association; world heart federation; international atherosclerosis society; and international association for the study of obesity. Circulation. 2009;120(16):1640-1645.

5. Grundy SM. Pre-diabetes, metabolic syndrome, and cardiovascular risk. Journal of the American College of Cardiology. 2012;59(7):635-643.

6. Shera AS, Basit A, Fawwad A, et al. Pakistan National Diabetes Survey: prevalence of glucose intolerance and associated factors in the Punjab Province of Pakistan. Primary care diabetes. 2010;4(2):79-83.

7. Raghupathy P, Antonisamy B, Fall CHD, et al. High prevalence of glucose intolerance even among young adults in south India. Diabetes Research and Clinical Practice. 2007/08/01/2007;77(2):269279.

8. Jeppesen C, Bjerregaard P, Jørgensen ME. Dietary patterns in Greenland and their relationship with type 2 diabetes mellitus and glucose intolerance. Public health nutrition. 2014;17(2):462-470.

9. Walsh EI, Jacka FN, Butterworth P, Anstey KJ, Cherbuin N. The association between Western and Prudent dietary patterns and fasting blood glucose levels in type 2 diabetes and normal glucose metabolism in older Australian adults. Heliyon. 06 2017;3(6):e00315.

10. Kyrou I, Tsigos C. Stress hormones: physiological stress and regulation of metabolism. Current opinion in pharmacology. 2009;9(6):787-793.

11. Siddiqui A, Madhu S, Sharma S, Desai N. Endocrine stress responses and risk of type 2 diabetes mellitus. Stress. 2015;18(5):498-506.

12. Reynolds RM, Labad J, Strachan MW, et al. Elevated fasting plasma cortisol is associated with ischemic heart disease and its risk factors in people with type 2 diabetes: the Edinburgh type 2 diabetes study. The Journal of Clinical Endocrinology \& Metabolism. 2010;95(4):1602-1608.

13. GARBELLOTTO GI, REIS FJ, FEOLI AMP, Et Al. SALIVARY CORTISOL AND METABOLIC SYNDROME COMPONENT'S ASSOCIATION. ABCD. Arquivos Brasileiros De Cirurgia Digestiva (São Paulo). 2018;31(1).

14. Andrews RC, Herlihy O, Livingstone DE, Andrew R, Walker BR. Abnormal cortisol metabolism and tissue sensitivity to cortisol in patients with glucose intolerance. The Journal of Clinical Endocrinology \& Metabolism. 2002;87(12):5587-5593.

15. Notarianni E. Cortisol: Mediator of association between Alzheimer's disease and diabetes mellitus? Psychoneuroendocrinology. 2017;81:129-137.

16. Chen S, Zhang Q, Dai G, et al. Association of depression with pre-diabetes, undiagnosed diabetes, and previously diagnosed diabetes: a meta-analysis. Springer; 2016.

17. Poongothai S, Anjana RM, Pradeepa R, Ganesan A, Umapathy N, Mohan V. Prevalence of depression in relation to glucose intolerance in urban south Indians-the Chennai Urban Rural Epidemiology Study (CURES-76). Diabetes technology \& therapeutics. 2010;12(12):989-994.

18. Hirokawa $\mathrm{K}$, Ohira $\mathrm{T}$, Nagayoshi $\mathrm{M}$, et al. Occupational status and job stress in relation to cardiovascular stress reactivity in Japanese workers. Preventive Medicine Reports. 2016/12/01/ 2016;4:61-67. 
19. Papaetis GS, Papakyriakou P, Panagiotou TN. Central obesity, type 2 diabetes and insulin: exploring a pathway full of thorns. Archives of medical science: AMS. 2015;11(3):463.

20. Sefidbakht S, Johnson-Down L, Young TK, Egeland GM. High protein and cholesterol intakes associated with emergence of glucose intolerance in a low-risk Canadian Inuit population. Public Health Nutrition. 2015;19(10):1804-1811. 